\title{
ДРЕВНИЕ НЕКРОПОЛИ:
}

I. is
D

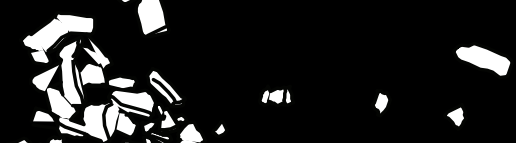
ПОГРЕБАЛ Ь НО -

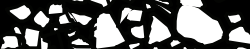

(4)

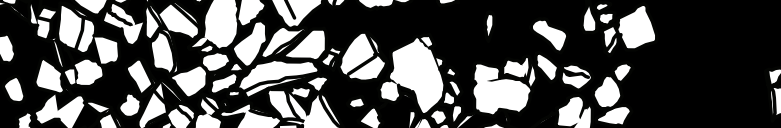

cos

ares

- L N J

Ifote $=25 \%$

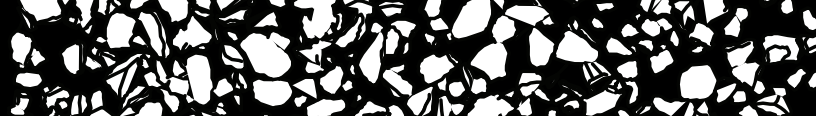

(3)

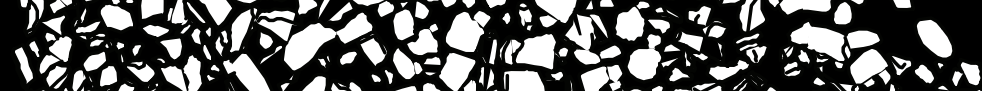

\section{8}

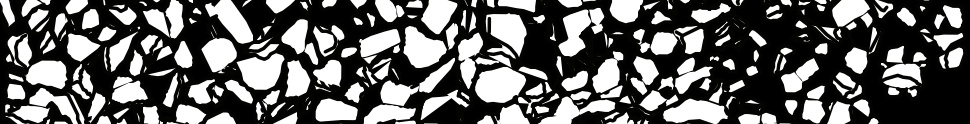

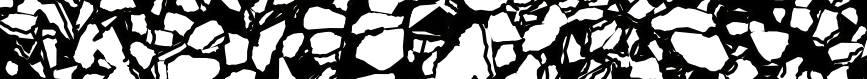

If

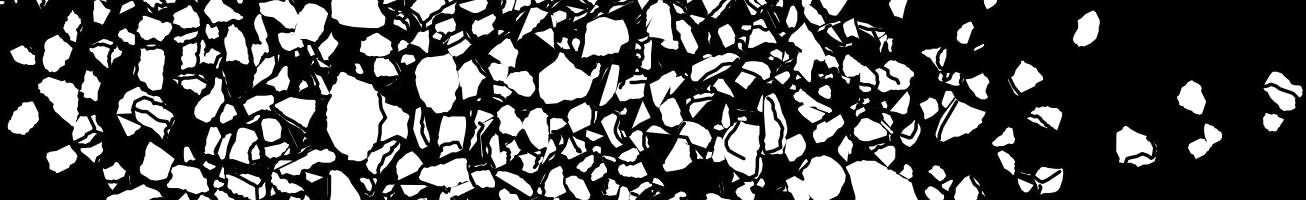

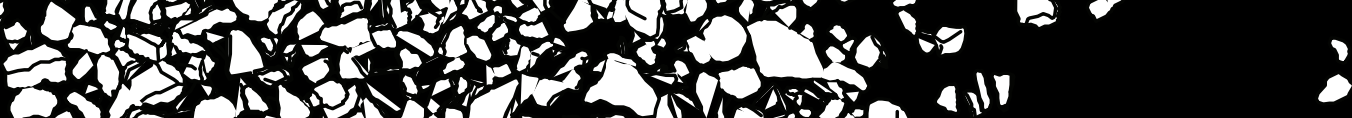

- STrer in

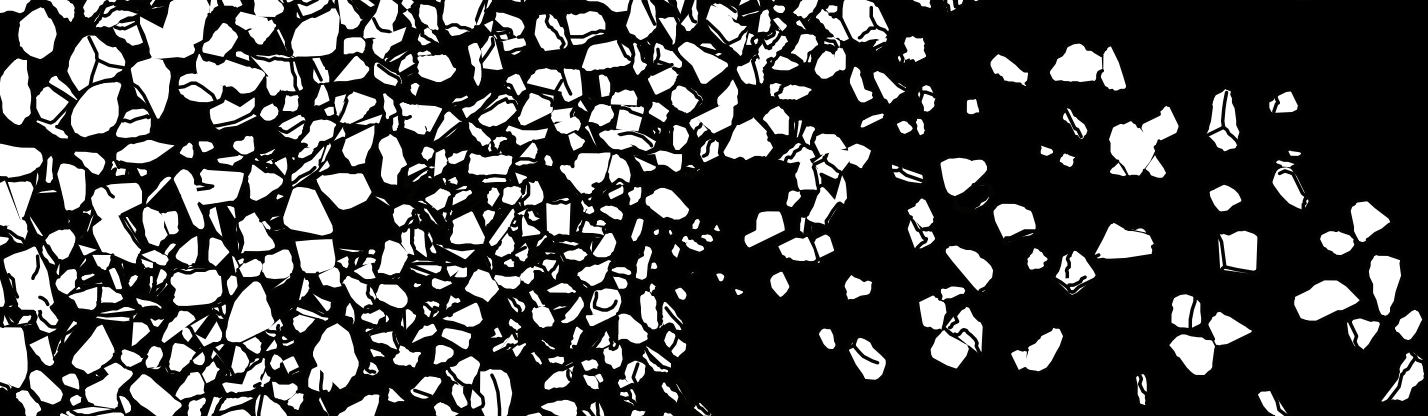

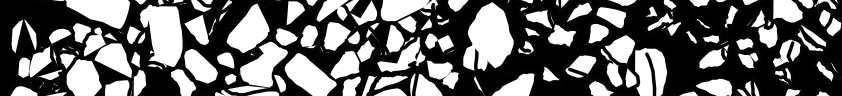

or 1 (1) 
RUSSIAN ACADEMY OF SCIENCES

INSTITUT FOR THE HISTORY OF MATERIAL CULTURE

THE STATE HERMITAGE MUSEUM

PROCEEDINGS. VOL. 47

\section{ANCIENT NECROPOLISES - \\ FUNERAL AND MEMORIAL RITUALISM, ARCHITECTURE AND PLANNING OF NECROPOLISES}




\author{
РОССИЙСКАЯ АКААЕМИЯ НАУК \\ ИНСТИТУТ ИСТОРИИ МАТЕРИААЬНОЙ КУАЬТУРЫ \\ ГОСУААРСТВЕННЫЙ ЭРМИТАЖ \\ ТРУАЫ ИИМК РАН. ТОМ 47
}

\title{
АРЕВНИЕ НЕКРОПО $И$ - \\ ПОГРЕБААЬНО-ПОМИНААЬНАЯ ОБРЯАНОСТЬ, ПОГРЕБААЬНАЯ АРХИТЕКТУРА И ПААНИРОВКА НЕКРОПОАЕЙ
}




\section{Аревние некропоми - погребамьно-поминацьная обрядность, погребахьная архитектура и планировка некропомей. Труды ИИМК РАН. Т. 47. - Санкт-Петербург, ИИМК РАН, Гос. Эрмитаж. - 256 с., ил.}

УтвержАено к печати Ученым советом ИИМК РАН

Approved for publication by the Academic Board of IHMK RAS

Редакционная каллегия: Е. Н. Носов (отв. реА.), М. Е. Килуновская, Н. А. Аазаревская, С. А. Яценко Editorial board: E. N. Nosov (editor-in-chef), M. E. Kilunovskaya, N. A. Lazarevskaya, S. A. Yatsenko

\section{Перевод на английский язык А. В. Семёнов \\ English translation: A. V. Semenov}

Pецензенты: Аоктор исторических наук В. А. Аапшин, доктор исторических наук А. Ю. Алексеев, кандидат исторических наук В. А. А^ёкшин

Reviewers: Doctor of Historical Sciences V. A. Lapshin, Doctor of Historical Sciences A. U. Alekseev, Candidate of Historical Sciences V. A. Alekshin

Предлагаемый читателю сборник явАяется публикацией материалов преАставительного межАународного Круглого стола «Аревние некрополи: погребально-поминальная обрядность, погребальная архитектура и планиграфия некрополей», проведенного в Петербурге в ноябре 2016 г. Он является второй из задуманной серии подоб̈ных встреч, посвященных малоисследованным аспектам погребальной обрядности, отражению в материалах археологии ментальности и субкультурной специфики. В публикуемых текстах особое внимание уделяется закономерностям внутренней планировки некрополей и святилищ, межАисциплинарному исследованию памятников такого рода, редким формам погребальных и надмогильных сооружений, обрядам обезвреживания умерших, в том числе с их черепами, человеческих жертвоприношений, реконструкции средневековых наземных склепов (выглядящих сейчас как курганы) и т.п. Тексты размещены в хронологической последовательности от неолита к позднему средневековью. Сборник будет полезен археологам, религиоведам, этнографам, историкам и всем интересующимся древней религией и культурными корнями ряда современных традиций.

We are glad to offer this digest to the readers. This is the publication of the materials of representative international Round table «Ancient necropolises: funeral and memorial ritualism, architecture and planning of necropolises», which took part in St.Petersburg, November 2016. It is second in series of similar meetings, dedicated to the little-explored aspects of funeral ritualism. One of those aspects is the reflection of mentality and sub-cultural specifics in archaeological materials. In the published texts special attention is paid to the regularities of internal planning of necropolises and sanctuaries, interdisciplinary research of this type of sites, rare forms of burial constructions, "disarming" rituals with bodies and sculls, human sacrifices, reconstruction of the medieval land crypts (which now look like barrows), etc. Texts are arranged in chronological sequence from Neolithic to Late medieval. Digest would be useful for archaeologists, ethnologists, religious scholars, historians and everyone who wish to study ancient religions and cultural roots of some modern traditions.

На Аицевой стороне обложки: могильник Эки-Оттуг 2, курган 1, Тыва

ISBN 978-5-93572-816-8
(C) Институт истории материальной культуры РАН / Institute for History of Material Culture RAS, 2018

(C) Государственный Эрмитаж /

The State Hermitage Museum, 2018

(C) Авторы статей / Autors of papers, 2018 


\section{СОАЕРЖАНИЕ}

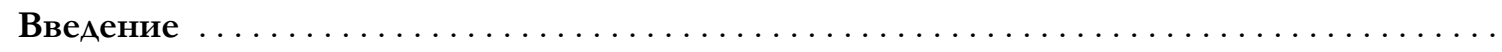

Перцева М. А. Ямы с фигурными выемками - особый вид погребений среднего бронзово-

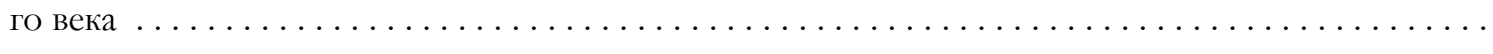

Ковахев А. А. Могильные ямы, моделированные по форме повозки, в Синьцзяне и Восточном Казахстане: их датировка и происхождение $\ldots \ldots \ldots \ldots \ldots \ldots \ldots \ldots \ldots \ldots \ldots \ldots$

Куприянова Е. В., Кириялов А. К. Роль и функции рва в погребальных комплексах эпохи бронзы Южного Зауралья $\ldots \ldots \ldots \ldots \ldots \ldots \ldots \ldots \ldots \ldots \ldots \ldots \ldots \ldots \ldots \ldots \ldots \ldots \ldots \ldots \ldots \ldots \ldots \ldots \ldots \ldots \ldots$

Рафикова Я. В. Антропоморфные стелы в погребальной обрядности эпохи позАней бронзы

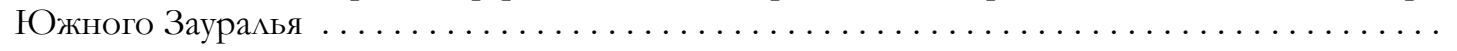

Мазаретов И. П., Морозов С. В., Помяков А. В. Новые данные о манипуляцих с черепами в погребальном обряде окуневской культуры $\ldots \ldots \ldots \ldots \ldots \ldots \ldots \ldots \ldots \ldots \ldots \ldots \ldots$

Усманова Э. Р. Кефацотафия по-андроновски (по материалам погребений Аисаковской ок-

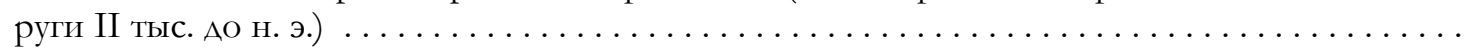

Боковенко Н. А. Вход в погребальное сакральное пространство у древних народов Средне-

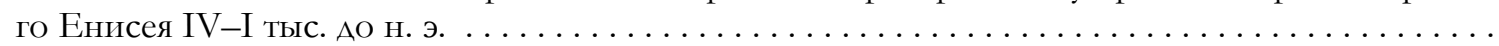

Ташбаева К. И. К семантике входов и дромосов в срубных конструкциях ранних кочевни-

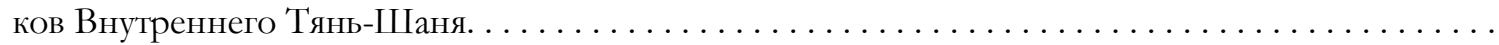

Агумьников С. М. О топографии и планировке могильникова белозерской культуры При-

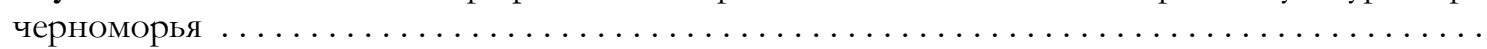

Малюкевич А. Е., Агульников С. М. Курганные некрополи Анестровского Правобережья

Кимуновская М. Е. Погребальные памятники Тувы от древности до средневековья . . . . . . . .

Кисель В. А. Человеческие жертвоприношения могильника Аогээ-Баары в Туве . . . . . . . . .

Семенов ВА. А. Планиграфия могильников Суглуг-Хем I и Суглуг-Хем II в Туве (III-II вв.

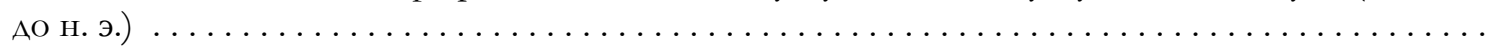

Бородовский А. П. Погребальное пространство в контексте политкультурности (по материалам Быстровского некрополя эпохи раннего железа на Верхней Оби) . . . . . . . . . . . .

Шишкин А. С., Волков П. В., Зубова А. В., Кишкурно М. С. Выставление голов у носителей каменской культуры Верхнего Приобья (по материалам Быстровского некропо я) .... .

Субботин А. В. Курганные некрополи тагарской культуры на юге Назаровской котловины ..

Акумов А. Г. «Время котов». Великолепные полтора века мемориалов тагарских нобилей ...

Вадецкая Э. Б. Отражение в колцективных могилах Енисея представлений о смерти инди-

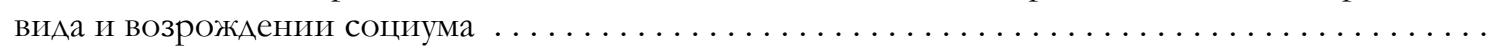

Козменко Р. А. ОбряА обезвреживания погребенных в Нижнем Побужье в античный период 164

Федоров В. К. Вторжения в могилы единоплеменников при совершении новых захоронений у ранних кочевников Южного Ура^а VI-I вв. до н. э. . . . . . . . . . . . . . . .

Сиротин С. В. П^аниграфическое отражение основных этапов сооружения курганного могильника Переволочан I в Зауральской Башкирии $\ldots \ldots \ldots \ldots \ldots \ldots \ldots \ldots \ldots \ldots \ldots \ldots$

Ивченко А. В. Постпогребальная обрядность на некрополе Ольвии . . . . . . . . . . .

Помин С. В. Об ограблении скифских курганов в Северном Причерноморье . . . . . . . . . 206

Симонян А. Е., Атоянц Е. А. Некрополь Тейшебаини . . . . . . . . . . . . . . . . . 216

Яценко С. А. Возможности анализа планиграфии малых сарматских некрополей . . . . . . . 224 
Анарух С. И., Тощев Г. Н. Археологические культуры Северного Причерноморья в фокусе Мамай-Горы

Смагулов Е. А. Место наземных склепов в погребальном обряде раннесредневековой СреА-

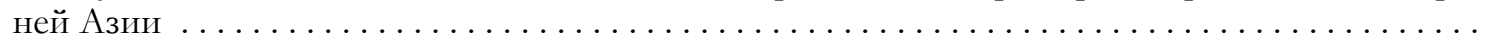

Список сокращений 251

Сведения об авторах 


\section{CONTENTS}

Introduction

Pertseva M. A. Pits with figured recesses - special type of burial constructions of middle Bronze

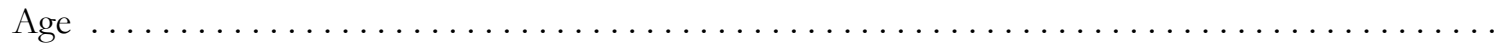

Kovalev A. A. Grave pits modelled by the shape of cart in Xinjiang and Eastern Kazakstan: dating

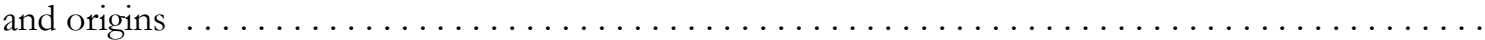

Kupriyanova E. V., Kirillov A. K. Role and functions of a moat in burial complexes of Bronze Age of Southern Trans-Urals.

Rafikova Ya. V. Stone anthropomorphic steles in the funeral rites of late Bronze age of Southern

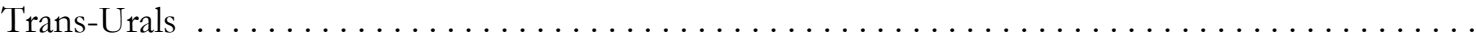

Lazaretov I. P., Morozov S. V., Polyakov A. V. New data on manipulations with sculls in the

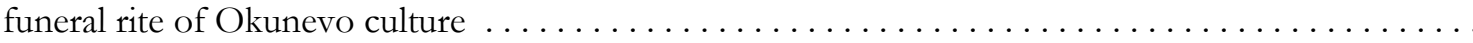

Usmanova E. R. Kefalotaphy in Andronovo culture (by the materials from burials of Lisakovskaya

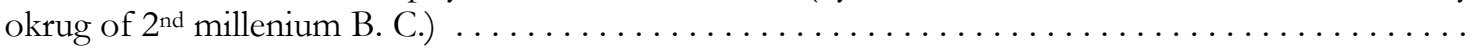

Bokovenko N. A. Entrance into the sacred funeral space among the ancient peoples of Middle

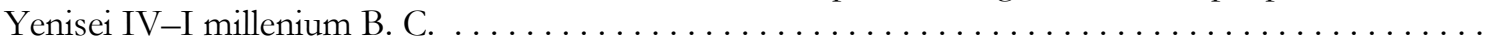

Tashbaeva K. I. To the semantics of dromoses and entrances in the timber constructions of Inner

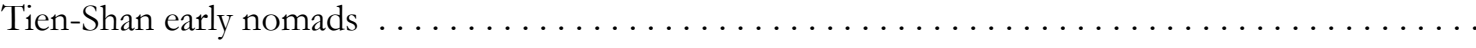

Agulnikov S. M. About topography and planning of Belozerskaya culture cemeteries . . . . . . . 79

Malyukevitch A. E., Agulnikov S. M. Barrow necropolis of the Dniester Right Bank . . . . . . 86

Kilunovskaya M. E. Burial sites of Tuva from primeval to medieval ages $\ldots \ldots \ldots \ldots 2$

Kisel V. A. Human sacrifices on Dogae-Baary cemetery in Tuva . . . . . . . . . . . . . . . . . . 106

Semenov V1. A. Planigraphy of Suglug-Khem I and Suglug-Khem II cemeteries in Tuva (III-

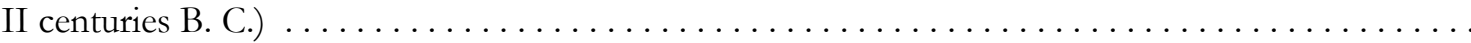

Borodovskiy A. P. Funeral space in the context of polyculturalism (on materials from Bystrovsky

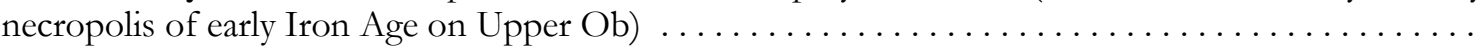

Shishkin A. S., Volkov P. V., Zubova A. V., Kishurko M. S. Exposing of heads among the bringers of Kamenskaya culture of Upper $\mathrm{Ob}$ (on materials from Bystrovsky necropolis) ........

Subbotin A. V. Barrow fields of tagarskaya culture in the south of the Nazarovo basin . . . . . . .

Akulov A. G. «Time of cats». Amazing century of Tagarskaya noble monuments . . . . . . . . .

Vadetskaya E. B. Death of an individual and revival of society reflected in collective graves of Ye-

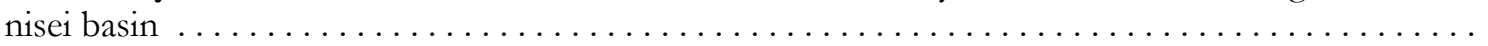

Kozlenko R. A. Rite of disarming of the buried bodies among population of Lower Pobuzhue ...

Fedorov V. K. Encroaching of tribe-mate graves during the creation of new burials among nomads

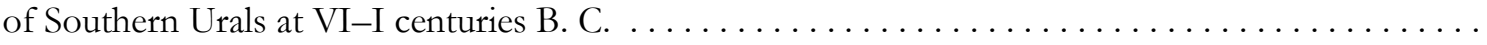

Sirotin S. V. Planigraphic reflection of the main constructional stages of Perevolochan barrow cemetery in Trans-Ural Bashkiria

Ivchenko A. V. After-funeral rituals on Olbia necropolis f . . . . . . . . . . . . . . . . . . . 201

Polin S. V. About the despoilment of Scythian mounds in Northern Black Sea Coast . . . . . . . . 206

Simonyan H. E., Atoyantz E. L. Necropolis Teyshebaini $\ldots \ldots \ldots \ldots \ldots \ldots \ldots \ldots \ldots \ldots \ldots \ldots$ 
Yatsenko S. A. Possibilities of minor sarmatian necropolises planographic analysis

Andruh S. I., Tosheev G. N. Archaeological cultures of Northern Black Sea Coast in focus of

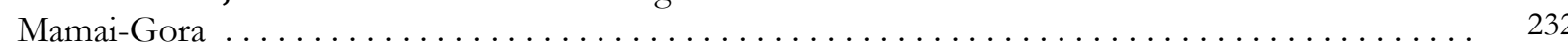

Smagulov E. A. Place of surface crypts in the funeral rite of early-medieval Central Asia . . . . . . 241

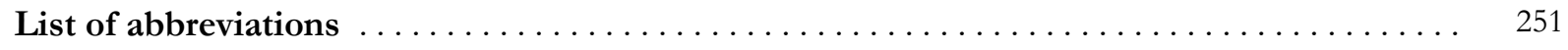

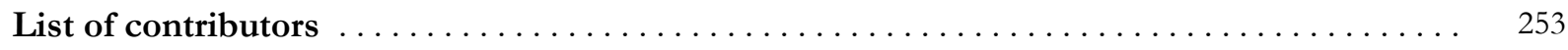




\section{К. И. Ташбаева}

\section{К СЕМАНТИКЕ ВХОАОВ И АРОМОСОВ В СРУБНЫХ КОНСТРУКЦИЯХ РАННИХ КОЧЕВНИКОВ ВНУТРЕННЕГО ТЯНЬ-ШАНЯ}

Статья посвящена некоторым особенностям погребального обряда отдельных племен ранних кочевников Внутреннего Тянь-Шаня, выраженных в конструкциях погребальных срубов могильника Кеден. Аелается попытка семантического объяснения этих конструктивных особенностей в виде обозначенных входов и Аромосов, хотя таковыми они не явАяются. Аается несколько вариантов их возможного назначения и объяснения.

Ключевые слова: Внутренний Тянь-Шань, могильник Кеден, ранние кочевники, саки, срубо, входы, Аромосы, Пазырыкский, Башадарский, Туэктинский могильники А^тая, Бесшатырский, Чиликтинский могильники Казахстана, обряд «протаскивания» и Ар.

В районе Внутреннего Тянь-Шаня Кыргызской Республики, в Нарынском р-не, на территории бывшего совхоза «8 марта», в течении трех полевых сезонов 1984, 1988, 1989 г. был исследован раннекочевнический могильник Кеден. Могильник располагался на второй надпойменной террасе правобережья р. Нарын, в 8-9 км юго-западнее от центральной усадьбы совхоза, в южной части широкой ровной террасы.

Могильник насчитываА около сотни курганов, расположенных по южному краю террасы, отдельными компактными группами (рис. 1). В центральной части могильника выделялась цепочка, вытянутая по Аинии север-юг из восьми крупных курганов, высотой до 2-2,5 м, Аиаметром 22-30 м.

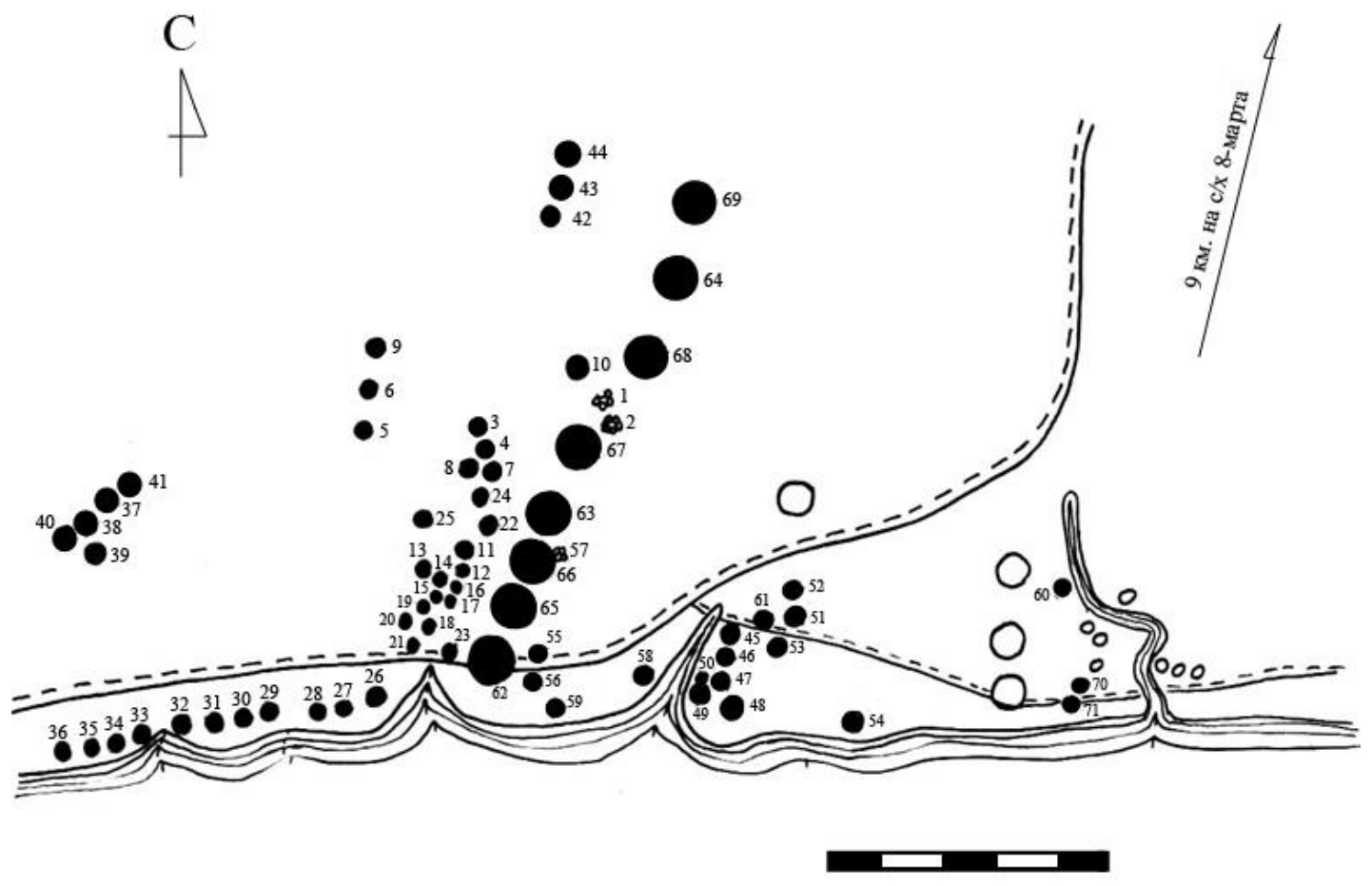

Рис. 1. П^ан могильника Кеден

В могильнике за три сезона были раскопаны 71 курган, в том числе и восемь крупных, расположенных цепочкой. В основной массе захоронения в курганах совершались в грунтовой могильной яме, вытянутой по Аинии запад-восток, перекрытых деревянным накатом или каменными плитами. 


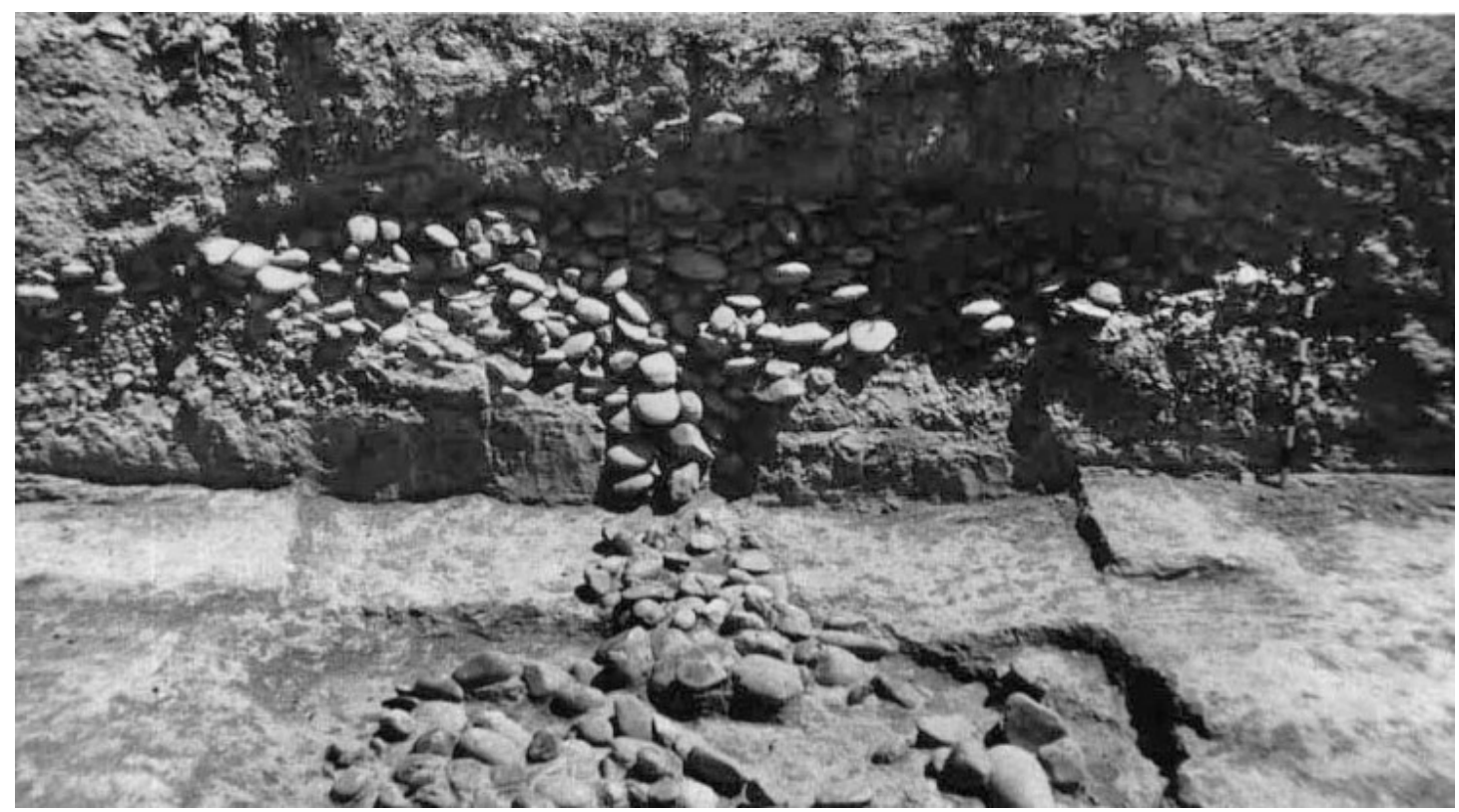

Рис. 2. Могильник Кеден, курган 66. Разрез насыпи и часть каменной выкладки наА срубом

В Аанной статье мы остановимся на материалах, полученных в результате исследований восьми крупных курганов, так как захоронения в них были совершены в Аеревянных срубах, что было обнаружено впервые на территории Кырғызстана. Но и в последующие времена, вплоть до сегодняшних Аней, срубы могильника Кеден остаются пока единственными Аеревянными погребальными сооружениями А^я эпохи ранних кочевников в Кыргызстане, и им нет точных аналогий среди погребальных памятников Центральной Азии.

Во всех восьми курганах деревянные срубы из арчовых бревен были опущены в могильную яму. Могильные ямы были не глубокими, и, соответственно, срубы были невысокими (высота 1-1,2 м, в Авух случаях - до 2 м), но просторными (Алина 2,8-3,7 м, ширина 2-3,5 м) и имели перекрытия из таких же бревен, что и стены. Погребения были ограблены еще в Аревности, поэтому в срубах сохранились только части скелетов погребенных, фрагменты разбитых, иногАа раздавленных керамических сосудов и незначительные предметы погребального инвентаря. Иногда по сохранившимся in situ костям ног и Аругих частей скелета можно было определить, что погребенные традиционно были положены вытянуто, на спине, головой на запац (Ташбаева, 1995; 1996).

Расположение курганов в цепочке в центре могильника, крупные размеры их насыпей и просторные срубы в ямах свидетельствуют об особом статусе погребенных в этих восьми курганах, а также сохранившиеся фрагменты золотых нашивных бляшек на олежАу, наличие более многочисленных керамических сосудов говорит о богатстве погребального инвентаря в них, к сожалению, ограбленных почти Аочиста еще в Аревности.

Об особом статусе погребенных свидетельствуют и конструктивные особенности насыпей курганов в отличие от рядовых захоронений. Если попытаться реконструировать процесс захоронения, то это выглядит следующим образом. Выкапывалась просторная могильная яма, в которую опускали деревянный сруб. Затем на пол сруба, без деревянного настила, помещали умершего (одного), раскладывали обязательный сопроводительный инвентарь и перекрывали потолок сруба деревянными бревнами. Поверх перекрытия набрасывали плотным слоем уплощенные камни или валуны высотой до 1-2 м, диаметром, превышающим размеры могильной ямы. Затем, поверх каменной наброски, насыпали слой земли в 1-1,5 м. Получившуюся таким образом небольшую насыпь плотно обкладывали камнями в один-Ава или три слоя, называемую нами каменным панцирем. Поверх панциря вновь насыпали земляной слой высотой до 1-1,2 м и также укрепляли его панцирным слоем (рис. 2; 3, 1). От второго панциря в настоящее время сохранились только боковые части, что, естественно, произошло из-за постепенного оплыва верхушки насыпи и в результате уменьшения высоты кургана за прошедшие 2,5-2,7 тысячи мет. 
Возможно, такие насыпи возводились не одномоментно, в период захоронения умерших, а в течение более Алительного времени, когда совершались обязательные поминальные обряды. Таким образом, насыпи были укреплены каменными панцирными кладками в Ава, возможно и в три слоя при очень больших размерах курганов, что хорошо прослеживается по их разрезам (рис. 2 и 3, 1). Благодаря такой прочной конструкции насыпей сохранились их внушительные размеры в течение Алительного периода времени, а также она препятствова^а проникновению вцаги во внутрь, что способствовацо сохранению деревянных внутримогильных сооружений.
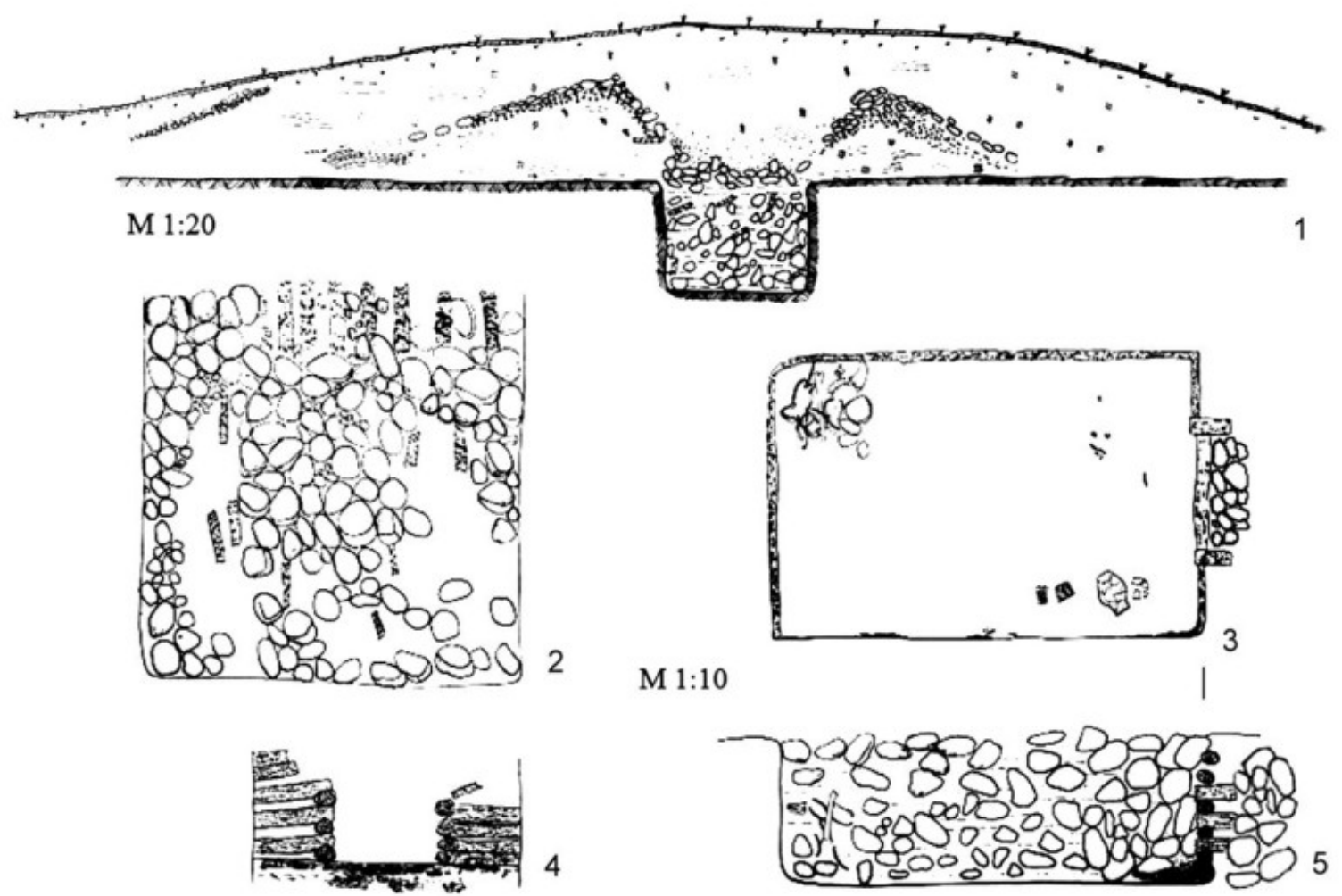

Рис. 3. Могильник Кеден, курган 62: 1 - разрез; 2 - каменная выкладка наА срубом; 3 - план сруба; 4 - вход-проем в восточной стене; 5 - разрез ямы со срубом

В Аанной работе мы хотим обратить внимание на наличие в срубных конструкциях могильника Кеден входов и Аромосов, обозначенных в восточной стене срубов. Судя по разрезам насыпей, где хорошо просматривались каменные забутовки Аромосов, входы были во всех курганах. Но по сохранности стен срубов нам удалось четко проследить входы только в трех случаях из восьми (курганы №№ 62, 65 и 66). Так, в кургане № 62 вход был четко обозначен. Он находился в восточной стене и был шириной 0,85-1 м. Вход имел порог, образованный самым нижним бревном. Порог от Ана ямы находился на высоте 0,20 м, то есть на толщину бревна. Края проема-входа были хорошо обработаны: небольшие обрубки бревен были положены между бревнами стен и перпендикулярно им в три-четыре ряда и выступали за пределы стены на 0,20 м (рис. 3, 3-5). За пределами сруба вход-проем был забутован крупными валунами.

В Авух Аругих курганах (курганы №№ 65 и 66) эти входы располагались в верхней части стены, ближе к потолку - перекрытию сруба. Они были шириной 0,60-0,75 м. и от них шел коридорчик типа Аромоса, Алиной около 4-6 м (рис. 4). Все Аромосы были плотно забутованы камнями, также как и небольшие пространства межАу срубами и стенами. Входы-Аромосы полностью оставались поА насыпью кургана и не выходили за пределы насыпи.

Принято считать, что погребальные сооружения чаще всего имитировали жилища Аюдей. В Аанном случае срубы тоже могли быть моделями жилищ, скорее всего, богатого сословия определенной части общества ранних кочевников. Вполне возможно, что высшее сословие общества ранних кочев- 
ников имело не только юрты в качестве своих жилищ, но и Аома в виде срубов, если они знали такую конструкцию Аля погребального обряда. Но надо иметь в виАу, что такие Аеревянные конструкции возможны были только в местах, где имелись месные массивы, или, по крайней мере, меса находились на более или менее доступных расстояниях.

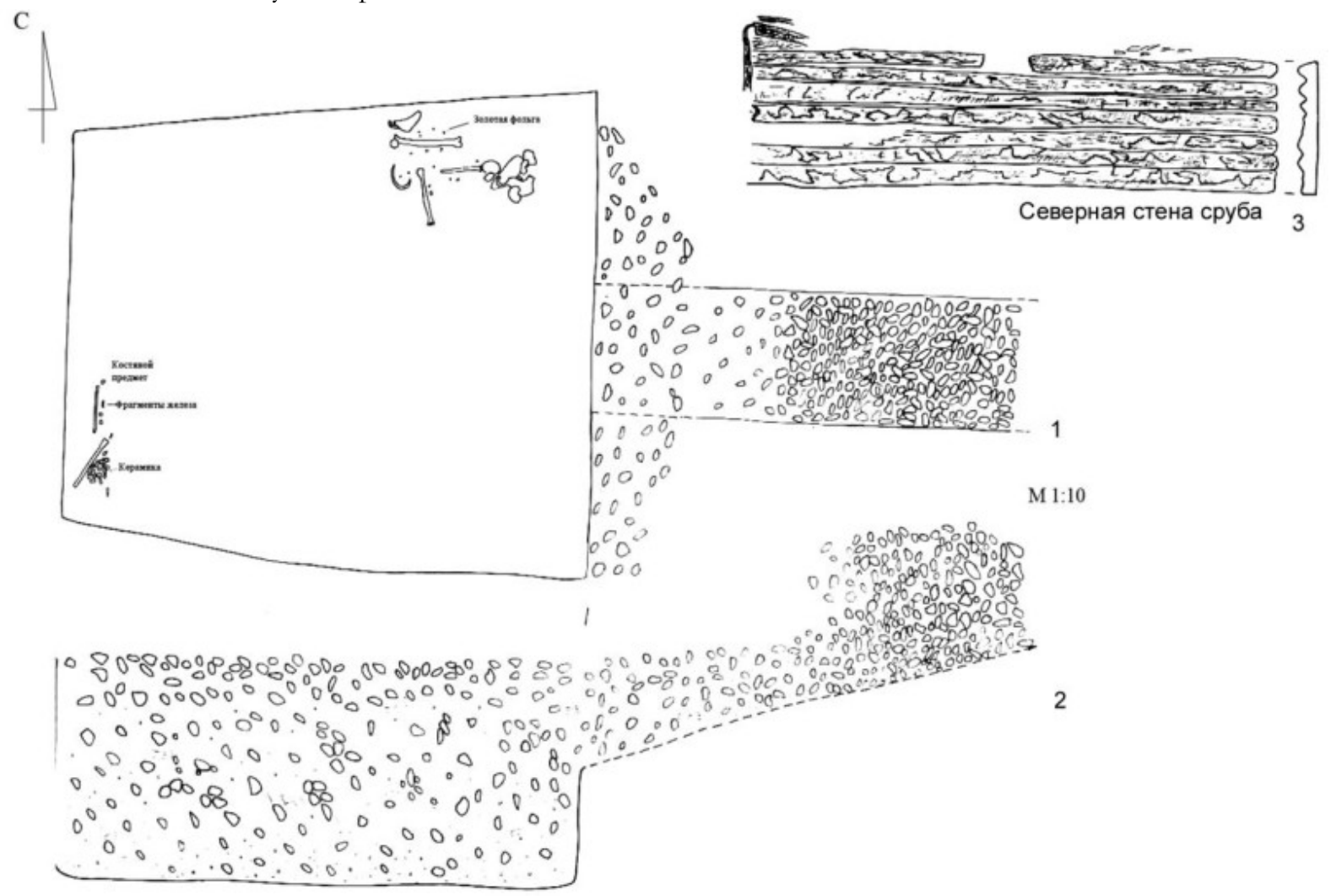

Рис. 4. Могильник Кеден, курган 66: 1 - план сруба и дромоса; 2 - разрез сруба и дромоса; 3 - северная стена сруба

В могильнике Кеден срубы были не наземными конструкциями, а опущенными в неглубокую яму, и умершего с сопроводительным инвентарем, без сомнения, помещали в погребальное место через верх. И в этом случае такой вход, как в кургане № 62, был явной имитацией двери, и вход выступал за стену сруба Аишь на 0,20 м и упирался в грунт. Но в Авух Аругих случаях (курганы №№ 63 и 66), эти входы располагались высоко от пола сруба и за пределами сруба, они наклонно поднимались выше, имея Аоже на Аревнем горизонте глубиной всего лишь 0,15-0,30 м. Видимо, когда сооружали насыпь, то в насыпи прокладывали и Аоже Аромоса, сразу плотно забутовывая его камнями. Считать их грабительскими казами у нас нет оснований. Грабители прорубали свои мазы прямо сверху, в то время как все входы и дромосы могильника Кеден располагались строго в восточной части, имели прямые минии форм, были выложены плоскими или уплощенными камнями. Это были дромосы, вернее, их имитации, проложенные специально в соответствии с принятым обрядом захоронения определенной категории Аюдей общества ранних кочевников.

Наличие этих входов в срубах, опущенных в яму, и их расположение не совсем понятны. Выполнять роль входов, через которые совершали погребения умерших, они не могли, каковыми, например, явАялись Аромосы в катакомбных сооружениях гуннской эпохи. Им явно отводицось Аругое назначение. Естественно, возникает вопрос, Аля чего они предназначались?

Захоронения в срубах на территории Кыргызстана не встречались ранее, если не считать Соколовского и Ажергесского курганов в Иссык-Кульской котловине, раскопанных экспедицией А. Н. Бернштама еще в 1949 г., где, судя по многочисленным остаткам деревянных фрагментов, возможно, была срубная конструкция, но четко проследить ее во время раскопок не удалось (Бернштам, 1952. С. 50-57). В основном же в могильниках Кыргызстана эпохи ранних кочевников захоронения совершались в грунтовых могильных ямах, перекрытых Аеревянным накатом или каменными плитами. 
В долине Кетмень-Тюбе, где было раскопано около 400 курганов в пятнадцати могильниках этого времени не встречена ни одна погребальная конструкция со срубом. Точно такая же картина наблюдается и в А^айской долине, где в свое время А. Н. Бернштамом и Ю. А. Баруздиным было раскопано большое количество погребений саков (Бернштам, 1952; Ташбаева, 1987; 2011. С. 36-53, 121-136). В Таласской и Чуйской долинах в курганах эпохи ранних кочевников также не встречена сруб̈ная конструкция внутримогильных сооружений.

При этом необходимо учитывать то, что раскопки курганов в Алайской, Таласской и Чуйской АОАинах проводились выборочно, по Ава-три или несколько рядовых захоронений некрупных размеров из могильников, в которых были иногда Ао нескольких десятков курганов. А в Чуйской Аолине и особенно в Иссык-Кульской котловине раскопки крупных элитарных курганов не производились вообще, и здесь не исключена вероятность наличия срубных конструкций. В этом плане отличны исследования, проведенные в долине Кетмень-Тюбе И. Кожомбердиевым в 60-80-х гг., в которых принимала участие и автор Аанной статьи, когАа раскопкам подвергалась большая часть курганов могильника или же исследовался целиком весь могильник (Кожомбердиев, 1973; 1975; 1986; Ташбаева, 1987; 2011). ОАнако, как было отмечено выше, в Кетмень-Тюбинской долине даже под большими насыпями крупных курганов, захоронения были совершены только в грунтовых ямах, перекрытых деревянным накатом.

Исследования во Внутреннем Тянь-Шане, проведенные под руководством К. Ташбаевой в 80-90 гг. XX в. также отличались от предылущих исследований А. Н. Бернштама и А. Кибирова тем, что раскопкам подвергались почти все курганы могильников, несмотря на их размеры и внешние Аанные насыпей. Только в результате таких исследований нам удалось получить более полную картину о погребальном обряде, материальной и духовной культуре ранних кочевников Тянь-Шаня, а также существенно новые Аанные в целом по культуре саков, населявших территорию Кыргызстана в I тыс. Ао н. э. (Ташбавва, 1987; 1995; 1996; 2011; и Ар.). Эти Аанные позволяют также говорить об историко-культурных, а возможно, и этногенетических связях ранних кочевников Кыргызстана с населением сопредельных территорий, но более конкретно - Южной Сибири, Саяно-А^тая и даже Монголии.

Если обратимся к аналогиям за пределами Кыргызстана, то, в первую очередь, можно рассматривать погребальные конструкции могильника Бесшатыр в Илийской долине на территории Казахстана. При этом надо отметить, что деревянные конструкции могильника Бесшатыр явАяются наземными постройками, в отличие от Аругих срубных конструкций времени ранних кочевников Центральной Азии, опущенных в яму. Бесшатырские Аеревянные конструкции еще и не явАялись срубами в классическом понимании их сооружения, как отмечал К. Акишев, автор раскопок. Боковые стены камер Бесшатырского могильника были укреплены вертикально врытыми зажимающими столбами. Алинные кориАоры-дромосы, по высоте на 1-2 м превышающие высоту камер, состоящие из двух отсеков, были также наземными. Наземным расположением деревянной конструкции погребальных камер и необычно высоких Аромосов погребальные сооружения Бесшатыра вообще отличаются от всех остальных синхронных памятников Центральной Азии (Акщщев, Кущаев, 1963. С. 27-87) и Ао сих пор не имеют аналогий. ОАнако назначение Аромосов здесь как входов в погребальную камеру очевидно. Хотя, конечно, возникает вопрос, к чему надо было возводить такие высокие и Алинные коридорообразные сложные входы? Но это вопрос погребального обряда Аанной группы сакских племен, который, без сомнения, требует углуб̆ленного изучения.

Интересны срубные конструкции с Аромосами-входами, обнаруженные в элитных захоронениях Чиликтинских курганов Восточного Казахстана, где Аромосы также были проложены в восточной стороне и не очень заглублены в землю, были невысокими, Алинными, но имели деревянное перекрытие. Автор раскопок считает, что они имели как практическое значение, так и ритуальномировоззренческое. К сожалению, отсутствие в публикациях чертежей элитарных погребальных сооружений и особенно их разрезов (Толеубаев, 2013. С. 204-207 и Ар.) затрудняет понимание конструктивных особенностей этих сооружений. 
Основная же территория, где распространены захоронения в срубах в эпоху ранних кочевников это Южная Сибирь, А^тай и Монголия. В элитных курганах пазырыкской культуры также наличествует сруб, опущенный в глубокую могильную яму, но здесь отсутствуют входы и Аромосы, что было прослежено по материалам Пазырыкского, Башадарского, Туэктинского и Аругих могильников А^тая и сопредельных территорий (Грязнов, 1950; Руденко, 1953; 1960; Грач, 1980; Полосьмак, 1994; Кирюоин и др., 2003; и Ар.). ОАнако наше внимание привлекло то, что в Пятом Пазырыкском кургане на Алтае в южных стенах сруба (срубы были двойными) был прорублен проем размером 0,70-0,60 м, куда были вставмены семь бревен, заклиненных в стенке камеры таким образом, чтобы они придавливали крышку саркофага-колоды (Руденко, 1953. С. 54-56).

Таким образом, срубные конструкции могильника Кеден Внутреннего Тянь-Шаня наличием имитированных входов и входов-Аромосов явцяются весьма своеобразными и на сегодняшний день не имеют точных аналогий в срубных погребальных конструкциях синхронного времени. Входы-Аромосы могильника Кеден наводят нас на мысль, что элитные погребальные сооружения имели сложную конструкцию и внушительные размеры, а также укреплялись так прочно не только Аля того, чтобы сохранить их от грабителей и увековечить гробницы усопших вожАей родов и племен, но еще и Аля иных целей.

В поисках разгадки этой конструктивной особенности курганов могильника Кеден мы натолкнумись на информацию, что Аревние египтяне на плоскости стены своих гробниц обязательно высекали рельеф, изображающий Аверь. Это было просто изображение Авери, которую невозможно было открыть, но по поверьям египтян, именно через нее душа покойного должна была попасть в коридор, называемый Ра Сетау, по которому Ауша усопшего выходила в потусторонний мир - Ауат. По преАставлениям Аревних египтян, Аорога в иной мир начиналась с тоннеля, коридора - Ра Сетау (Авери Протаскивания), который соединял мир живых с миром мертвых.

По-вилимому, известный в этнографии с обозримого прошлого обряд «протаскивания» умершего имел архаичные корни, уходящие во времена фараонов, который имел место и у Аругих древних нароАОв и племен, в частности, у некоторых сакских племен, проживавших в Аревности на территории Кыргызстана. Суть этого обряда заключалась в вере и ритуале символического пропускания или продевания человека через какое-либо сквозное отверстие, проем или просвет, в результате чего происходило его «перерожАение и очищение от всего отрицательного». В похоронном же обряде подразумевацось, что Ауша умершего Аолжна была пройти через символическую Аверь, что Аавало ему очищение от всего земного и возможность перехода в иной потусторонний мир.

Возможно, Аожные входы и Аромосы в срубных конструкциях могильника Кеден можно объяснить этим Аревним представлением и считать их своеобразным указателем пути в иной мир. Иначе невозможно объяснить наличие входа-Авери, ведущего в никуда, то есть упирающегося просто в грунт и который невозможно было использовать как вход при совершении захоронения, то есть при помещении умершего на его погребальное место, также как можные входы-Аромосы, которые фактически не могли быть использованы как входы. Скорее всего, как и в гробницах Аревних египтян, они являлись симвоАическими входами и Аорогой в потусторонний мир. По преАставлениям Аюдей, проживавших в этой местности в середине I тыс. Ао н. э. и похоронивших своих богатых сородичей особым способом в срубах с Аожными входами согласно принятому ритуалу, - проход в потусторонний мир находился строго на Востоке, судя по расположению входов и направлению Аромосов.

В этнографической митературе известен обычай, распространенный у многих славянских народов, в том числе и у русских, как вынос умершего не через входную Аверь, а через окно или специально проделанное отверстие в жилище ${ }^{1}$. Считалось, что Аверь служит живым, а окно или отверстие - мертвым. В этом случае обряд «протаскивания» имел несколько иное назначение или объяснение, а именно обмануть покойника, «запутать его слеА». Согласно верованиям, мертвец мог вернуться в Аом только известным ему при жизни путем. Хотя одновременно с таким похоронным обрядом, в это же время существовало представление, что обряд «протаскивания» или «пронимания» мог исцелить больного чело-

\footnotetext{
${ }^{1}$ Выражаю большую благодарность своей комлеге $\Lambda$. Ведутовой за информацию об этом обряде.
} 
века, чаще всего детей. В таких случаях больного пропускали через какое-то отверстие, развилку, специально изготовленный венок и т. А., что символизировало очищение его от всего негативного и постепенное исцеление, что фактически значит переход в иное состояние. Возможно, вынос, то есть «протаскивание» умершего через окно, первоначально мог, как и в Аревности, иметь такой же очищающий смысл и означать переход умершего в иное состояние.

По прохождении тысячелетий, вероятно, смысл и назначение этого погребального обряда несколько изменились. Из назначения, указующего и, соответственно, облегчающего Ауше умершего путь в Царство мертвых, очищающего его от земных грехов, обряА «протаскивания» стац иметь иное назначение, и он продолжал бытовать в среде населения на широкой территории. Первоначальное особое отношение к смерти, как к своеобразному путешествию Ауши человека в иной мир, где он продолжал свое бытие; естественно связанный с ним культ предков; похоронному обряду, выражавшееся в возведении таких сложных, внушительных размеров внутримогильных и наземных частей погребальных конструкций, какие мы наблюдаем повсеместно для периода ранних кочевников; а также снабжение умершего пищей и всеми необходимыми предметами Аля жизни в Аругом мире, чаще всего Аорогих, изготовленных из золота и украшенных мастерски, ювелирно, видимо. постепенно перерождается в представление как о враждебной силе, роковом неизбежном зле, могущем принести вред оставшимся живым родственникам.

Смерть человека всегда была загадочна, необъяснима и потому сильно мифологизирована, главным мифом из которых было бессмертие Ауши и вера в потустороннюю жизнь. ОАновременно смерь пугала живущих. И если ранее обряА «протаскивания» имел цель очищения умершего от земных грехов

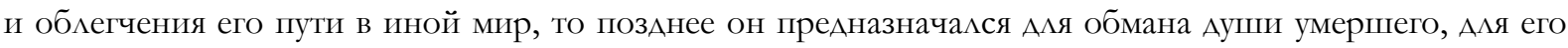
запутывания, чтобы он не нашел обратной дороги в свой дом и не навредиц родственникам.

Возможно, и это назначение обряда «протаскивания», как запутывания, обмана покойного, также могло иметь архаичные корни. Например, ложные входы и Аромосы могильника Кеден могли служить не только как указатели и проходы в иной мир, но также и Аля запутывания и обмана умершего. Ведь ему точно указывацось, куда нужно идти, то есть в никуда, туда, где Аальше дороги нет и где Аромос также не имел выхода. Не зря дверной проем в кургане № 62 и Аромосы в Аругих курганах были не про-

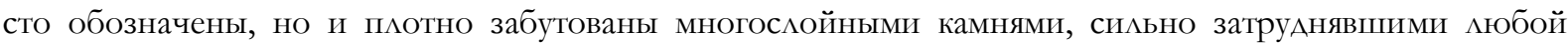
проход через них, Ааже Ауше умершего.

В связи с этим вспомним, что в Пятом Пазырыкском кургане крышка саркофага-колоды была приАавлена семью бревнами, не просто положенными поверх крышки, а сложным путем заклиненных прочно через специальный проем, вырезанный в стенках двойного сруба. И это было сАелано, вероятно, не столько с целью сохранения от грабителей, которые проникнув в погребальную камеру, могли устранить такую преграду (что и было слелано), сколько Аля погребенного внутри колоды, чтобы он не мог выйти из нее и навредить живущим родственникам или сородичам. Снабдив покойного погребальной пищей и необходимыми предметами обихода, обеспечивали ему своеобразную «жизнь в достатке» в погребальной камере.

Возможно, отмечаемые исследователями сложные катакомбы и Алинные коридоры, проложенные под некоторыми погребальными камерами элитных захоронений в Бесшатырском, Чиликтинском могильниках, в Пазырыкских курганах и Ар. (Руденко, 1953; Акишев, Кушаев, 1963; Толеубаев, 2013), имели такой же смысл и назначение, как запутывание покойного, а не как место поминальных тризн по прошествии времени.

У кыргызов, оказывается, также имел место обряд «протаскивания» через окно 2 , правда, встречавшийся очень редко, и только у тех, кто проживал в осеАло-земледельческих районах, то есть в домах, а не в юртах. В юртах не возможно было прорубить окно или отверстие в стене. В настоящее время этот обрял почти не встречается, и потому не привлек внимания этнографов. Скорее всего, это Аелалось в тех случаях, когда семью посещали частые смерти близких родственников, и чтобы умерший не «унес»

\footnotetext{
2 Выражаю большую благодарность колмеге Т. Арзыбаеву, поделившемуся своими наблюдениями.
} 
с собой еще кого-нибудь, чаще всего Аетей, его пытались обмануть таким образом. Этот обряА мог иметь место и тогАа, когАа умерший при жизни обладал какими-то особыми способностями, как, например, шаманскими, «черным глазом», «ведьминскими», не всегда добрыми, приносящими вреА окружающим, и такой человек внушал страх окружающим, а его смерть усугубляла негативное отношение к нему.

Вполне возможно, что издавна известный у кыргызов и у Аругих кочевых народов обряд помещения умершего в отАельную, специально постав енную ААя этого юрту, и вынос покойного из этой юрты, кроме практических привилегий, изначально преследовал ту же цель - ограАить живущих от мертвеца и проводить его в последний путь из жилища, которого он не знац при жизни. Скорее всего, этот обряд также мог уходить корнями в эпоху ранних кочевников. Ведь ограниченное жизненное пространство юрты противоречило элементарным этическим нормам Аюдей: питаться, спать, Аетям нахоАиться здесь же, пока в течение определенного времени покойник готовился к погребению. Поэтому помещение покойника в отАельную юрту могло практиковаться еще с очень ранних времен, с эпохи раннего железа, а возможно и ранее, когАа основным жилищем была юрта или подобная ей конструкция.

Таким образом, рассмотренные срубные конструкции могильника Кеден со своеобразными имитациями входов и Аромосов являются в некотором роде уникальными. Они позволяют проследить интересные элементы погребального обряда определенного рода или племени общества ранних кочевников, которые проживали в Аанной местности Аостаточно Алительное время, суАя по количеству курганов. Их верования и обряд погребения отличались от обряда и верований основной массы кочевого общества I тыс. Ао н. э., населявших не только территорию Кыргызстана, но и всей Центральной Азии. Они, как и все Аругие племена, верили в потустороннюю жизнь и в своих погребальных сооружениях устраивали можные двери и проходы, указывающие путь в иной мир. ОАновременно с указанием Ауше покойного пути, куда следует иАти, они огражАали его семью и сородичей от возможного его возвращения и нанесения вреда живущим. И этот обряд был известен с глубокой Аревности, еще со времен египетских фараонов, затем центральноазиатских ранних кочевников и сохранился вплоть Ао современности, закономерно в течении такого Алительного времени несколько трансформируясь, из-

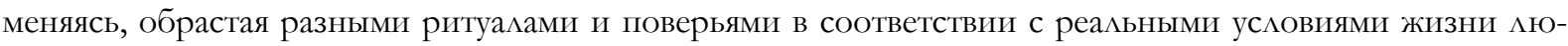
Аей в определенные исторические периоды.

Акишев К. А., Кушаев Г. А. Аревняя культура саков и усунеи долины реки Или. Алма-Ата, 1963.

Бернштам А. Н. Историко-археологические очерки Центрального Тянь-Шаня и Памиро-Алая. М., 1952. МИА; № 26.

Грач А. А. Аревние кочевники в чентре Азии. М., 1980.

Грязнов М. П. Первый Пазыгрыкский курган. А., 1950.

Кирюшин Ю. Ф., Степанов Н. Ф., Тишкин А. А. Скифская эпоха Горного Алтал. Ч. ІІ: Погребально-поминальные комплексы пазыгьикской культуры. Барнаул, 2003.

Кожомбердиев И. Новые данные о сакском периоде в долине Кетмень-Тнбе // АО 1973 года. М., 1973.

Кожомбердиев И. Саки Кетмень-Тюбе // Страничь истории и материальной культуры Киргизстана. Фрунзе, 1975.

Кожомбердиев И. Культура ранних кочевников Западного ТяньШаня (по материалам курганных могильников VТ в. до н. э. - VII в. н. э.): дис. ... канд. ист. наук в форме науч. доклада. 1., 1986.

Полосьмак Н. В. Стерегущие золото грифьг. Новосибирск, 1994.
Руденко С. И. Культура населения Горного Алтая в скифское время. М.; 1., 1953.

Руденко С. И. Культура населения Центрального Алтая в скиф ское время. М.; 1., 1960.

Ташбаева К. И. Культура ранних кочевников Тянь-Шаня и Алая (вопрось хронологии и локальныгх вариантов): дис. ... канд. ист. наук. 1., 1987.

Ташбаева К. И. Новые аспекть в культуре ранних кочевников Тянь-Шаня // Из истории и археологии древнего ТяньШаня. Бишкек, 1995.

Ташбаева К. И. Археологические комплексы ранних кочевников Тянь-Шаня // Аревний и средневековый Кьргъззтан. Бишкек, 1996.

Ташбаева К. И. Культура ранних кочевников Тянь-Шаня и Алая (І тыс. до н. э.). Бишкек, 2011.

Толеубаев А. Т. Проблемь эпохи бронзы и раннего железного века Казахстана. Изб. труды и статьи: Т. 1. Алмать, 2013. 